\title{
Klimawandel Wer stoppt die Zerstörung?
}

$\mathrm{E}$ s werden tagtäglich weltweit etwa 100 Tier- und Pflanzenarten ausgerottet. Gut hundertmal mehr als in »normalen« Zeiten der Erdgeschichte. Die globale Erwärmung schreitet beschleunigt fort, man rechnet realistischerweise mit einer »4${ }^{\circ}$-Welt«, einer Welt, die im Durchschnitt um $4{ }^{\circ} \mathrm{C}$ wärmer ist als in einer normalen geologischen Warmzeit. Man muss mit katastrophalen Folgen für alle Küstenregionen sowie mit ständigen Wetterkapriolen, Dürren und Überschwemmungen rechnen.

Die Dynamik der Artenvernichtung und des Klimawandels nimmt vorläufig weiter zu, und die Wirtschaftspolitik praktisch aller Länder ist darauf ausgerichtet, die Dynamik zu verstärken statt abzuschwächen.

Wie kann diese zerstörerische Dynamik gebremst und schließlich gestoppt werden? 